\title{
ROSALÍA DIANTE DA CIENCIA E DA TECNICA
}

Francisco Díaz-Fierros Viqueira Universidade de Santiago de Compostela doi: 10.17075/rcsxxi.2014.003 

André Poullain (1985), ao analizar a obra poética de Rosalía de Castro, chegaba á conclusión de que a maioría das súas composicións estaban moi pouco influídas polas lecturas e afeccións literarias da escritora. Estas lecturas, que non eran poucas, ficaban a un lado diante dos seus sentimentos, afectos e impulsos, que constituían o principal motor da súa inspiración. De aí o antiintelectualismo co que define o autor francés a súa poesía. De todas as maneiras, para comprender mellor a personalidade da escritora e, mesmo, para indagar sobre as claves interpretativas da súa obra, son fundamentais todo un conxunto de estudos (a maioría deles feitos para e despois do congreso internacional de 1986) que tratan de analizar as influencias do momento histórico que lle tocou vivir. Estas influencias basearíanse no coñecemento das características sociais, políticas e mesmo filosóficas do seu tempo. Así mesmo, estudos comparativos coa literatura espańola e universal sérvennos para coñecer os estilos e correntes literarias coas que se podían relacionar.

A ciencia moderna, con achegas tan importantes e de tanta pegada popular como o darwinismo e os progresos da medicina, foi pouco a pouco impregnando o século XIX español cos seus conceptos, métodos e solucións. E a técnica, con adiantos tan evidentes como o ferrocarril e as novas industrias que comezaban a aparecer nos arredores das cidades, mostraba con orgullo as novas posibilidades que se lle estaban a abrir ao ser humano. Os xornais e as revistas que nacían por todas as partes, como outra das características deste século, non deixaban de recoller estas novidades. Así, no período da vida de Rosalía, desde 1837 a 1885, apareceron en España 245 revistas científicas ou técnicas (Algaba, 2000), e as xeralistas, cun bo tratamento gráfico, e polo tanto con moita difusión, como El Semanario Pintoresco (1836-1857), El Museo Universal (1857-1869) ou a Ilustración Española y Americana (1857-1869), non deixaban de ter seccións permanentes con estas temáticas. Mesmo a literatura de Clarín, Galdós ou Pardo Bazán, entre outros (Pratt, 2001), incluían entre os seus personaxes, cada vez con máis frecuencia, enxeñeiros e científicos. 
Galicia tampouco foi allea a estas correntes e controversias que xurdían diante da ciencia e da técnica do momento, como puido ser o caso dos debates sobre o darwinismo e nos que bos cońecidos do matrimonio Murguía, como foi o caso do farmacéutico Rodríguez Carracido, tiveron un protagonismo especial (DíazFierros, 2009). Tamén as publicacións periódicas, non tan abundantes coma no Estado, pero tampouco escasas, se facían eco destas cuestións, como ocorría co Semanario Instructivo (1838), El Recreo Compostelano (1842), Revista de Galicia (1850, 1880), Galicia (1860), etc., cabeceiras en que eran frecuentes subtítulos como «Periódico de Agricultura, Ciencias Naturales y Artes», «Periódico de Ciencias, Literatura y Arte», «Semanario de Literatura, Ciencias y Artes», etc.

Algúns dos escritores estranxeiros que cita Rosalía na súa obra, como Ernst Hoffman ou Alan Poe, tampouco ignoraban a ciencia na súa temática, como é o caso da muller autómata de Hoffman ou o poema «A ciencia» de Poe (Cunninghan e Jardine, 1990). Nos dous casos, a súa posición diante da ciencia é ambivalente: conécena e utilízana como argumento, pero tamén son críticos co empirismo dominante, que permite e que limita o voo da fantasía, da que eran mestres eses dous autores.

Malia todo isto, a presenza da ciencia e da técnica na obra de Rosalía é moi escasa. Só citas illadas e non moi frecuentes falan desas realidades nas súas poesías e novelas. Aínda así, dada a transcendencia que a ciencia e a técnica tiveron como conformadoras da mentalidade colectiva do século dezanove español, estimo que paga a pena intentar facer un achegamento a estas cuestións, aínda inéditas, nos estudos rosalianos.

Unha primeira cuestión en relación co tema que nos ocupa e que podería servir de introdución é a relativa á posición de Rosalía diante da idea ¿̇ou mito? do progreso, no que a ciencia e, sobre todo, a técnica se constituían como os seus principais fundamentos. Coa chegada do liberalismo e o ascenso da burguesía como clase, era de común aceptación a idea rousseauniana da bondade do home así como unha fe cega no progreso continuo da humanidade. Ademais, o papel que os adiantos técnicos desempeñaban neste desenvolvemento expresábao con claridade o economista galego Manuel Colmeiro:

El mundo camina hacia un estado de perfección ideal acercándose de siglo en siglo a ese último y supremo grado de común felicidad... Hoy la palabra cruza el mundo en un 
instante, la locomotora devora por mar y tierra el espacio, las montańas se horadan, se saltan los valles profundos, la agricultura rinde dobles cosechas, y se construyen máquinas que multiplican y perfeccionan los artefactos (Principios de economía politica, 1859).

Recentemente, Rábade Villar (2012) tratou parcialmente o tema do progreso en Rosalía desde o punto vista da contraposición das tradicións galegas fronte á nova sociedade que se estaba a conformar en España e Galicia, sobre todo despois da Revolución Gloriosa do 68. Considera que a posición de Rosalía diante do progreso non é clara xa que, por unha banda, como afín ás ideas renovadoras dos republicanos e dos homes da Institución Libre de Enseñanza (ILE), defende as novidades que chegan pero, por outra banda, decátase de que todas elas non teñen capacidade para dar resposta ás preguntas máis fondas e transcendentes que pode formular o ser humano («Luz e progreso por todas partes... pero / as dudas nos corazóns», Follas novas).

Estas dúbidas poderían estar na base do carácter máis ou menos aséptico que manifestan outras referencias ao progreso que se atopan na obra de Rosalía, como pode ser o coñecido diálogo coa Musa da introdución a El caballero de las botas azules:

Hasta que Dios llame a los hombres a juicio, viviré sin envejecer jamás, ni perder nada de mis encantos: ayer fui el vapor, hoy seré musa; mañana... me llamaré movimiento continuo o cuadratura del círculo... ¿quién sabe lo que de mí saldrá?... Pero la ciega humanidad seguirá mis pasos y me rendirá culto, proclamándome la soberana del mundo.

Este mesmo carácter, dunha certa obxectividade, atópase nun poema de En las orillas del Sar, no que fai referencia á obra colectiva que supón a construción do progreso a partir das achegas científicas:

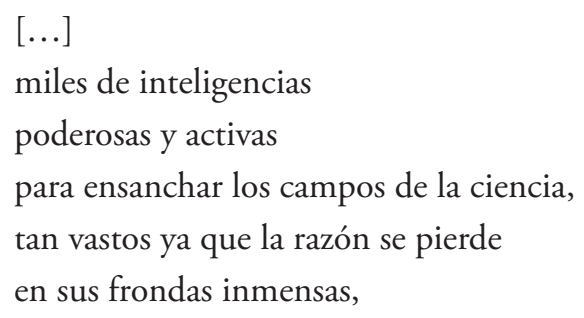


acuden a la cita que el progreso

les da desde su templo de cien puertas.

De todas as maneiras, esta idea do progreso sérvelle a Rosalía para criticar os problemas derivados da vida urbana, sobre todo na súa novela Flavio, onde «dialoga claramente con la problematización de la idea de progreso, lo que, de modo implícito, parece sostener la primacía del modo de vida rural» (Rábade Villar, 2012). E, tamén, nun tema claramente rosaliano, como é o da denuncia da submisión das mulleres, utiliza esta mesma idea do progreso para contrapoñela á realidade feminina do seu tempo ( $\ldots .$. en vano se habla de adelantos, de progreso; las mujeres siguen atormentadas, las unas teniendo que hacerlo todo, que trabajar para si y para los demás; las otras haciéndose vestir y desnudar la mitad del día». El caballero de las botas azules).

No que atinxe á súa posición diante da ciencia, Rosalía semella aliñarse co movemento romántico do escepticismo e crítica que Chateaubriand inaugurou nos comezos do século, segundo o cal o acto creador só dependía das musas, sen axudas da razón, nin referencias á verdade e á lóxica («Aínda que se xuntasen mil cerebros, xamais compoñerían a obra que sae da cabeza de Homero» [Dhombres, 2002]).

En España, Becker, na súa coñecida «Rima IV», retoma estes mesmos sentimentos da incapacidade e tamén da incompatibilidade da ciencia co misterioso e descońecido:

\footnotetext{
Mientras la humana ciencia no descubra

las fuentes de la vida,

y en el mar o en el cielo haya un abismo

que al cálculo resista,

mientras la humanidad siempre avanzando

no sepa a do camina,

mientras haya un misterio para el hombre,

¡habrá poesía!
}

En Rosalía, a crítica da ciencia céntrase fundamentalmente en dous aspectos: en primeiro lugar, participa dos mesmos sentimentos románticos, xa comentados, 
da incapacidade da ciencia para estimular as fibras do sentimento e da sensibilidade estética no ser humano:

Existe algo en el hombre de todas edades, que no se educa ni ciñe por completo a las exigencias de la razón ni de la ciencia, así como suele sobreponerse también a todas las ignorancias y barbaries que han afligido a la humanidad entera. Y este algo, es el exceso de sensibilidad y sentimiento que de ciertos individuos se hallan dotados [...].

[...] penétrate de su espíritu reconcentrándote en ti mismo, y llegarás a comprender en parte lo que te digo; no apelando a la ciencia ni a la fría razón, que son para el caso ciegas y sordas, y como quien dice su antítesis, sino únicamente al sentimiento, que es el único que tiene el poder de comunicarnos con lo que ni se mide ni se palpa y es invisible a los mortales ojos (El primer loco).

Neste senso, considera mesmo a loucura como un estado que pode ter acceso a realidades intanxibles ás que a ciencia e os razoamentos están incapacitados para chegar. Estas realidades poden tamén ser a base da xenialidade ou da excelencia artística. De aí que ideoloxías que toman as bases empíricas da ciencia como o seu primeiro fundamento, como o positivismo, son totalmente contrarias ao xenio creador («en estos tiempos en que el positivismo mata el genio y en que la poesía tiene que cubrirse de terciopelo para entrar en sociedad», La hija del mar).

Esta valoración contraria ao positivismo contrasta, en certa maneira, coas afinidades ideolóxicas e políticas que se supón que ten Rosalía con relación a ILE (Davies, 2012; Rábade Villar, 2012) pois os institucionistas, dentro das naturais matizacións e variantes, eran, en xeral, defensores convencidos e militantes dunha boa parte dos presupostos filosóficos que sustentaban esa ideoloxía (Núné, 1975).

En segundo lugar, a crítica de Rosalía á ciencia céntrase tamén na súa incapacidade para dar respostas a todos os interrogantes que se poden formular desde o máis fondo do ser humano (la ciencia es tan vana como estéril; en ciertos casos su poder se reduce tan sólo a conocer su impotencia-La Hija del Mar). Valoración pesimista que fica aínda máis clara neste poema de En las orillas del Sar: 


\begin{abstract}
En vano el pensamiento
indaga y busca en lo insondable ¡oh ciencia!

siempre al llegar al término ignoramos

qué es al final lo que acaba y lo que queda.
\end{abstract}

Os problemas de saúde que afectaron a Rosalía e á súa familia durante case toda a súa vida son, posiblemente, a razón de que lles dedique unha atención especial ás ciencias médicas nalgunha das súas novelas, diante das que toma, a través dos seus protagonistas, posturas ás veces moi contrastadas. Nalgúns casos, coa esperanza de que o estudo e as atencións médicas dean resultados, como en La hija del mar:

Paso las noches sobre los libros escudrińando los misteriosos secretos de la ciencia para ver si consigo al fin hallar algún remedio a tan terrible enfermedad.

Te ruego — añadió después con acento suplicante- que estudies de nuevo todos los libros de tu ciencia, que recorras los hospitales, que busques, en fin, un medio, sea el que quiera, para salvarla.

Pero, na maior parte dos casos, contaxiada do escepticismo xeral co que Rosalía mira a ciencia, a súa actitude é desesperanzada e negativa:

[...] sólo nos resta sufrir y llorar y arrojar al fondo del océano esos libros que se llaman libros de ciencia.

[...] todo lo que acabas de decir no es más que una loca aberración de vuestra ciencia confusa..., a veces hacéis alarde de creencias y de esperanzas que no tenéis (La hija del mar).

Finalmente, ten tamén unha conciencia bastante clara de que cos males morais (psicolóxicos, diriamos hoxe) a ciencia médica do seu tempo tiña moi pouco que facer:

No tardó en sorprenderme la visita del médico, a quien con toda cortesía que me fue posible hice saber que con mi enfermedad, hija del cansancio y disgusto moral, nada tenía que ver la ciencia (El primer loco). 
Francisco Sanz del Río (1814-1869), o filósofo que inspirou os homes da ILE, propoñía «completar la luz de la razón con la ayuda del sentimiento» (Gómez Molleda, 1966) e Giner, que deseñou toda a súa proposta pedagóxica, defendía a necesidade dunha educación en que se fixese realidade un diálogo entre a ciencia e a arte. Rosalía, malia a súa proximidade ideolóxica a estes homes, non foi quen de seguilos nestes presupostos, xa que na súa obra o pouco que se transloce en relación coa súa maneira de entender a ciencia deixa ver unha valoración pesimista e, sobre todo, unha certa antítese coa sensibilidade e sentimentos que están nas bases do xenio artístico. Neste senso, está máis próxima ás teses dun certo romanticismo tardío de raíces idealistas, ao que nin tan sequera foron alleos poetas tan ben cońecedores das realidades científicas, como Victor Hugo ( A ciencia desencanta a natureza e seca o corazón», Dhombres, 2002).

Certamente, esa percepción sobre os límites da ciencia está máis próxima a algunha das valoracións actuais (Prigogine, 1997) que ao optimismo utópico do que daban mostra os homes do dezanove. Pero tamén é verdade que ese diálogo intercultural entre a ciencia e as «outras culturas» que hoxe se defende como unha das necesidades máis perentorias destes tempos esixiría unha visión optimista, pero matizada, da ciencia e da técnica, posición que semella non compartir Rosalía. 


\section{REFERENCIAS BIBLIOGRÁFICAS}

Algaba, A. (2000): «Las revistas científicas en la España del siglo XIX», Scripta Nova, 69 (27), (www.ub.edu/ geocrit/sn-69.htm).

Colmeiro, M. (1859): Principios de economía politica, Madrid, Librería de D. Ángel Calleja.

Cunnighan, A. / N. Jardine (1990): Romanticism and the Sciences, Cambridge, Cambridge Univ. Press.

Davies, C. (2012): «La loca, sońando: Rosalía de Castro (1837-1885)», en H. González Fernández / M.a do

C. Rábade Villar (eds.), Canon y subversión. La obra narrativa de Rosalía de Castro, Barcelona, Icaria, 27-43.

Dhombres, N. (2002): «Romanticism, Science and Poetry», en J. Montesinos, J. Ordóńez e S. Toledo (eds.), Ciencia y Romanticismo, La Orotova, Fundación Canaria Orotava de Historia de la Ciencia, 71-80.

Díaz-Fierros Viqueira, F. (2009): "Científicos galegos no debate sobre o darwinismo en España», en F. Díaz-Fierros Viqueira (ed.), O Darwinismo e Galicia, Santiago de Compostela, Universidade, 145-174.

Gómez Molleda, D. (1966): Los reformadores de la España contemporánea, Madrid, CSIC.

NúŃEz Ruiz, D. (1975): La mentalidad positiva en España: Desarrollo y crisis, Madrid, Túcar Ediciones.

Poullain, C. (1985): «Rosalía o el anti-intelectualismo», Insula, 463, 3-4.

Pratt, D. L. (2001): Signs of Science. Literature, Science and Spanish Modernity, since 1868, Indiana, Purdue Univ. Press.

Prigogine, I. (1997): El fin de las certidumbres, Madrid, Taurus.

Rábade Villar, M.a do C. (2012): «Rosalía de Castro y el mito del progreso. Elementos para una nueva política del tiempo», en H. González Fernández / M. a do C. Rábade Villar (eds.), Canon y subversión. La obra narrativa de Rosalía de Castro, Barcelona, Icaria, 79-97. 